\title{
A COMUNICAÇÃo EXTERNA NA POLÍCIA FEDERAL BRASILEIRA COM O USO DAS REDES SOCIAIS
}

\author{
João Carlos Girotto \\ Polícia Federal - MG \\ Politécnico de Leira (Portugal)
}

\begin{abstract}
RESUMO
Com a crescente difusão das tecnologias de comunicação e informação, o uso das redes sociais está presente em todas as classes e camadas da sociedade, que utilizam tais plataformas digitais para interagir, trocar e compartilhar conhecimentos e informações. Nesta conjuntura as empresas privadas e instituições públicas também passaram a utilizar este espaço digital; aquelas buscando ampliação de seu mercado, fidelização de clientes e aumento de vendas; estas, por sua vez, cumprindo função normativa de interesse social consistente em levar informação ao cidadão, destinatário de seus serviços, bem como melhorar sua imagem e grau de credibilidade perante o público, por meio de uma comunicação adequada das atividades realizadas cotidianamente. Neste cenário, o artigo em comento analisa as redes sociais utilizadas atualmente pela Polícia Federal brasileira (PF), observando seu alcance, atualidade e a receptividade do público que compartilha estas plataformas digitais.
\end{abstract}

Palavras-chave: redes sociais; Polícia Federal; sociedade em rede; plataformas digitais; internet.

"Ciência e tecnologia revolucionam nossas vidas, mas a memória, a tradição e o mito moldam nossas respostas”.

Arthur Schlesinger

\section{INTRODUÇÃ̃o}

Nos tempos hodiernos, nos quais nos deparamos com a chamada era da informação, presenciamos um cenário social em que novas tecnologias são postas à disposição das pessoas, em escala gigantesca, possibilitadas, em especial, pela inserção no mercado de aparelhos ele- 
trônicos conjugados com recursos de acesso à internet, que permitem maior facilidade e rapidez na comunicação interpessoal.

Este conjunto de elementos inclusive altera, de maneira substancial, hábitos ou determinados modos de comportamento (como exemplo, o fato de que o envio de telegramas foi eliminado em vários países, justamente em razão de facilidades oferecidas pelo aparato tecnológico posto à disposição). A Índia abandonou o uso do telegrama, em 2013, o governo decidiu acabar com o serviço, que sucumbiu frente a novas tecnologias (ÍNDIA, 2013). Em 2017, foi a vez da Bélgica eliminar o serviço, ante a baixa demanda dos anos anteriores (APÓS, 2017).

Parece-nos consensual que com o avanço das tecnologias de comunicação e informação e o advento da globalização, as relações interpessoais que estavam ligadas, sobretudo, às formas impressas, ao rádio e à televisão, modificaram-se, criando, por consequência, novas ferramentas, de fácil acesso, que permitem uma rápida troca de informações e atualização em tempo real.

Essa transição dos meios tradicionais massivos (rádio, televisão, jornal) para as mídias digitais permitiu que determinado evento com caráter noticioso, após ocorrido, em alguns minutos, chegasse aos habitantes de um grande centro europeu e, quase de maneira instantânea, aos moradores de um pequeno vilarejo de uma planície africana. Justamente este novo tempo que vivenciamos deu ensejo à democratização da informação, proporcionada, neste aspecto particular, pela utilização das redes socais.

No âmbito deste novo cenário de tecnologia comunicacional digital, os órgãos policiais e, neste contexto, a Polícia Federal (PF), também fazem uso de plataformas de redes sociais com a finalidade de levar ao público externo notícias acerca de seu trabalho cotidiano, referentes a atividades administrativas e de polícia, na manutenção da lei e da ordem.

A investigação aqui desenvolvida, acirrada pela curiosidade do tema e dentro dos estudos como mestrando em Comunicação e Media, no Politécnico de Leiria (Portugal), visa examinar a utilização das redes sociais na comunicação externa da PF quando da divulgação de suas ações, quer sejam de natureza policial ou administrativa. 
O artigo empregou a metodologia qualitativa exploratória, por meio de pesquisa bibliográfica em publicações dá área de comunicação social, e quantitativa, com a compilação de dados obtidos das redes sociais utilizadas pela PF.

Além disso, incontestável a pertinência e adequação do tema ao contexto atual, visto que o grau de confiabilidade da população na instituição Polícia Federal decorre diretamente de sua visibilidade midiática e adequação de seu produto informativo.

\section{A ERA DA INFORMAÇÃ̃o}

A partir do momento em que o Homem de Neandertal - considerado por muitos antropólogos ancestral direto do homem moderno (SANTOS, 2014) - passou a viver em agrupamentos e a criar formas básicas de organização para caça de animais, pesca e coleta de alimentos, a comunicação desempenhou papel crucial na sobrevivência e no próprio desenvolvimento da espécime, avançando com a invenção e utilização de estruturas linguísticas, tornando-se o ser humano um animal social.

Inicialmente, essa transmissão de informação e de conhecimento - que remete ao significado do verbo "comunicar" como "transmitir informação, estabelecer comunicação ou ter conexão" (COMUNICAR, 2020) -, realizava-se de forma rudimentar, não verbal, por meio de gestos, sons, grunhidos, desenhos e, com o passar dos tempos, alcançou o aspecto verbal com a constituição de pequenas palavras e na posterior criação do alfabeto e formação de textos escritos, vindo o homem a desenvolver plena capacidade de conceber, transmitir e informar adequadamente.

$\mathrm{Na}$ busca do desenvolvimento e para vencer distâncias, o ser humano criou diversas formas para transmitir informação, destacando-se a comunicação por meio de sons - como, por exemplo, através de tambores na África, sinos para transmitir a mensagem de que era a hora de ir à igreja, o uso do clarim que ecoava como um sinal de alerta entre recuar ou atacar em uma guerra (MARTINS et al., 2018) - e outros tantos meios convencionais, como o envio de mensagens por estafetas militares e o uso do pombo-correio. 
Com a criação do telégrafo, no século XIX, por Samuel Morse, - aparelho emissor de sons transmitidos em códigos para enviar mensagens de longa distância, que teve a primeira ocorrência em 1831 -, ocorreu um sobressalto no encurtamento do tempo para que o receptor tomasse ciência de determinada informação, mostrando-se tal invento um divisor de águas.

O uso do telégrafo de Morse permitiu grandes avanços, com o melhoramento de outras técnicas de comunicação e transporte aumentando o volume e a velocidade das transações, passou-se a exigir, também, uma nova forma de organização das relações entre compradores e vendedores, cuja ligação começou a ser feita por uma organização e uma estrutura de gestão (SUBTIL, 2014).

Na segunda metade do século XX, a ARPANET, primeira rede de computadores que entrou em funcionamento em 1969 nos Estados Unidos, mostrou-se um grande catalizador para a criação de novas tecnologias de difusão da informação, sendo o principal elemento para a invenção e o desenvolvimento da Internet (PEREIRA; SILVA, 2012) e permitindo a criação de outras tecnologias associadas.

É certo afirmar que depois do invento da televisão, em 1930, que passa a crescer sistematicamente, tornando-se dominante a cada ano, a Internet desponta como uma das 25 maiores inovações das últimas décadas, segundo lista elaborada por especialistas em tecnologia reunidos pelo Lemelson-MT Program (BENATTI, 2008), avançando a sociedade para a formação de uma grande comunidade global interconectada.

Igualmente oportuno salientar que, na última década, vivenciamos o surgimento de inéditos meios usados para comunicação, que ganharam maior funcionalidade, interatividade e rapidez na transmissão de informações, avanços possibilitados, sobretudo, por novos equipamentos (telefones, smartphones e tablets) que são disponibilizados no mercado, com acesso de praticamente todas as camadas da população.

1 Em 6 de janeiro de 1838, Samuel Morse demonstrou pela primeira vez o seu principal invento, o telégrafo, na Metalúrgica Speedwell, em Nova Jérsei, nos Estados Unidos. O telégrafo, aparelho que utiliza impulsos elétricos para transmitir mensagens codificadas através de um cabo, revolucionaria a comunicação de longa distância. 
A utilização de celulares conjugados com recursos de Internet chegou ao alcance de todos, eliminando ou diminuindo o uso de lanternas, rádios-relógios, agendas, máquinas fotográficas, filmadoras e muitas outras coisas, e mais, o aparelho tornou cada cidadão conectado e apto a ter determinada voz, permitindo a pessoas comuns tornarem-se, no mundo virtual, editor, repórter, dono de jornal e cameraman (KARNAL, 2019).

Os meios para as pessoas comunicarem-se vêm tendo consideráveis avanços, especialmente com o surgimento de novos atores nesse processo, que antes ficavam relegados a um cenário secundário. Conforme aponta Grassi e Marques (2018), a comunicação, que antes era de um para muitos (one-to-many communication model), hoje é caracterizada como sendo de muitos para muitos (many-to-many communication model), decorrente da constante e veloz evolução da tecnologia.

\section{REDES SOCIAIS NO CONTEXTO ATUAL}

Os termos redes sociais e mídias sociais são utilizados frequentemente como sinônimos, contudo, oportuno sublinhar que o vocábulo mídia social é mais comumente empregado para referir-se ao canal ou o meio pelo qual se desenvolve uma comunicação, ou seja, entendido também como o recurso pelo qual uma informação é transmitida (CAMPOS et al., 2009), ao passo que rede social diz respeito a espaços virtuais onde pessoas, grupos de pessoas e empresas se relacionam de forma constante.

As redes sociais estão profundamente relacionadas ao desenvolvimento de novas tecnologias de informação, com ligação umbilical ao avanço da chamada era do conhecimento, bem como a modificações culturais e de convivência social. O conceito de rede social (social network) foi utilizado pela primeira vez em 1954, pelo antropólogo britânico John A. Barnes (FIALHO, 2017).

Este conceito de rede engloba compreensões distintas no campo das ciências sociais, especialmente na antropologia e na comunicação, contudo, os diversos autores, inclusive Barnes, que em 1960 em seu artigo intitulado "Redes sociais e seu aspecto político" ampliou o 
conceito já utilizado por ele, afirmando que nas redes os indivíduos irão se articular a partir de interações e não, como havia formulado anteriormente, a partir de composições egocêntricas. Há, contudo, um ponto em comum nos diversos autores no que diz respeito ao conceito de rede - sua capacidade de articulação e rearticulação permanente (ENNE, 2004).

Releva notar que recentes avanços tecnológicos, especialmente a interconectividade trazida pela $w e b$, rede que conectou computadores em nível planetário, permitiram alterações consubstanciais nas concepções acerca da chamada mídia de massa, que antes era afeta à imprensa, ao cinema, ao rádio e à televisão (mídias tradicionais). Não se trata aqui de desqualificar ou desmerecer esses tipos de mídia que, a despeito do avanço considerável das redes sociais, ainda tem considerável poder de penetração em face a características societárias e geográficas.

\section{As NOVAS TECNOLOGIAS E AS MUDANÇAS DE COMPORTAMENTO}

Esse impulso tecnológico determinou uma mudança do tipo de comportamento nas interações socais e, por consequência, levou a um novo processo comunicativo, com implicações técnicas, éticas e morais (KUNSCH, 2007). Hoje, tornou-se quase raridade receber cartões impressos, alusivos ao Natal ou a qualquer outra data comemorativa. Convivemos com cartões digitais, apresentados em diversos modelos e escritos em diferentes textos, que permitem rápida personalização. Cartões em papel tornaram-se praticamente objetos relativos ao saudosismo.

Segundo Assunção, citando Foucault (2014), existem quatro tipos de tecnologias presentes na cultura ocidental (tecnologias de produção, tecnologias dos sistemas de signos, tecnologias de poder e tecnologias de si). O autor aponta como tecnologias de si aquelas que permitem aos indivíduos efetuarem, com seus próprios meios ou com a ajuda de outros, um determinado número de operações em seus próprios corpos, almas, pensamentos, conduta e modo de ser, permitindo uma transformação com intuito de alcançar um certo estado de felicidade, pureza, sabedoria, perfeição ou imortalidade (ASSUNÇÃO, 2019). Exatamente 
neste campo se inserem os personagens ativos e passivos das redes sociais, porquanto tais plataformas colocam à disposição novas ferramentas que permitem o compartilhamento instantâneo de vídeos, fotos e documentos, incorporando diferentes funcionalidades, permitindo maior credibilidade e autenticidade no envio de qualquer tipo de conteúdo.

Em que pese a existência de inúmeras redes sociais, estas mantêm uma estrutura base que consiste num registro na rede e na criação de um perfil com base nos dados pessoais do utilizador, que pode ser público, semipúblico ou privado (SAIOTE, 2013), permitindo a seu utilizador a estipulação de parâmetros quanto à visualização de dados de caráter subjetivo por parte de outro personagem que integra a plataforma.

\section{REDES SOCIAIS E SEUS PÚBLICOS}

Atualmente, existem inúmeros tipos de redes sociais, com diferentes finalidades e públicos-alvo, que têm foco em contatos profissionais, amizades, relacionamentos amorosos, pesquisas, dentre outros (HUGO; PAIVA, 2011), e que possibilitam o envio de vídeos, imagens, fotos, textos, mensagens de voz, compartilhamento de publicações etc., trazendo, assim, uma gama de modalidades de transmissão de informações.

O avanço tecnológico por que passam as telecomunicações, imprensa, rádio, televisão, computadores, Internet e transmissões via satélite, impele a sociedade a um novo comportamento e, consequentemente, a um modulado processo comunicativo social, com inúmeras implicações técnicas, éticas e morais (KUNSCH, 2007).

Cumpre mencionar que isso leva à criação de comunidades virtuais, as quais têm por base a formação de relações sociais, tal como no conceito tradicional, contudo, se distinguem pela ausência de espaço físico e por uma distância geográfica virtual: o espaço e o tempo colidem no ciberespaço. (COSTA, 2005, apud SAIOTE, 2013).

Neste caminho, a televisão deixou de ser o único meio partilhado por todas as classes e faixas etárias e, no panorama atual, em face do uso de redes sociais, vislumbramos grupos de pessoas que, muitas vezes, contam com indivíduos radicados em diferentes locais do globo 
e, mesmo assim, interagem de forma constante quanto a determinados assuntos ou informações.

As redes digitais não afetam somente códigos referentes ao binômio texto/imagem, como a imprensa tradicional televisiva, na qual a comunicação é por meio de imagem e som. A nova tecnologia digital, encampada pelas redes sociais, trouxe linguagens informativas que permitem integrar, de forma adequada, três códigos: texto, imagem e som (SALAVERRÍA, 2001).

Novos comandos foram incorporados a essas plataformas digitais, como curtir (like), compartilhar (share), visualizar, comentar, postar, seguir, tweet (número de publicações feitas no Twitter), e o uso de linguagem específica, como fazer uma selfie (autorretrato reproduzido e compartilhado).

\subsection{REDES SOCIAIS DE MAIOR USO}

Existem dezenas de redes sociais em uso na atualidade, contudo, estas surgiram à medida que foram aparecendo novas tecnologias, sobretudo em aparelhos móveis - celulares e smartphones - que começaram a ser vendidos a preços mais acessíveis, atingindo as classes da população de menor poder aquisitivo.

A primeira rede social reconhecida foi lançada em 1987 nos EUA e era designada como Six.degree.com (ACQUISTY, 2006; BOYD, 2008), ela permitia a criação de perfis, listagens de amigos e troca de mensagens entre os integrantes da rede, combinando diversas funcionalidades numa só plataforma (BOYD, 2006, apud SAIOTE, 2013).

Atualmente, são disponibilizados por empresas diversos tipos de plataformas de redes sociais destinadas à troca e ao compartilhamento de informações. Essas redes são empregadas de acordo com o objetivo do usuário, faixa etária, escolaridade e públicos.

Apenas a título ilustrativo, tomando-se como panorama o face$b o o k$, estudo desenvolvido por Madden et al. (2013), junto de 802 adolescentes (12-17 anos), apurou que o Facebook, à época, estava profundamente integrado ao quotidiano adolescente, sendo cada vez maior o número de informação pessoal partilhada (PEREIRA; MATOS, 2015). 
Convém assinalar que existem, hodiernamente, inúmeras plataformas de relacionamento na web: (i) redes sociais de entretenimento, como exemplo o YouTube; (ii) redes sociais de relacionamento, criadas com intuito de estabelecer e fortalecer laços (emprego, capacitações, valores) entre as pessoas (Facebook); (iii) redes sociais profissionais, cujos usuários têm em mira alcançar objetivos relacionados à atividade que se exercem por ofício (buscar e disponibilizar vagas, informar sobre capacitações, divulgar cursos e seminários), como exemplo cita-se o Linkedin e, ultimamente; (iv) as redes sociais de nicho, voltadas para uma parte do mercado altamente segmentado (Skoob).

De acordo com pesquisa divulgada pelo site Statista, em outubro de 2019, entre os 15 tipos de redes sociais mais utilizadas no mundo, o Facebook, o YouTube e o WhatsApp lideram o ranking; o Linkedin aparece em penúltimo lugar. O motivo deste panorama, ao que tudo indica, deve-se ao fato de que as pessoas se conectam na busca de entretenimento, interação pessoal e partilha de informações, ocupando os jovens papel de grande destaque neste protagonismo.

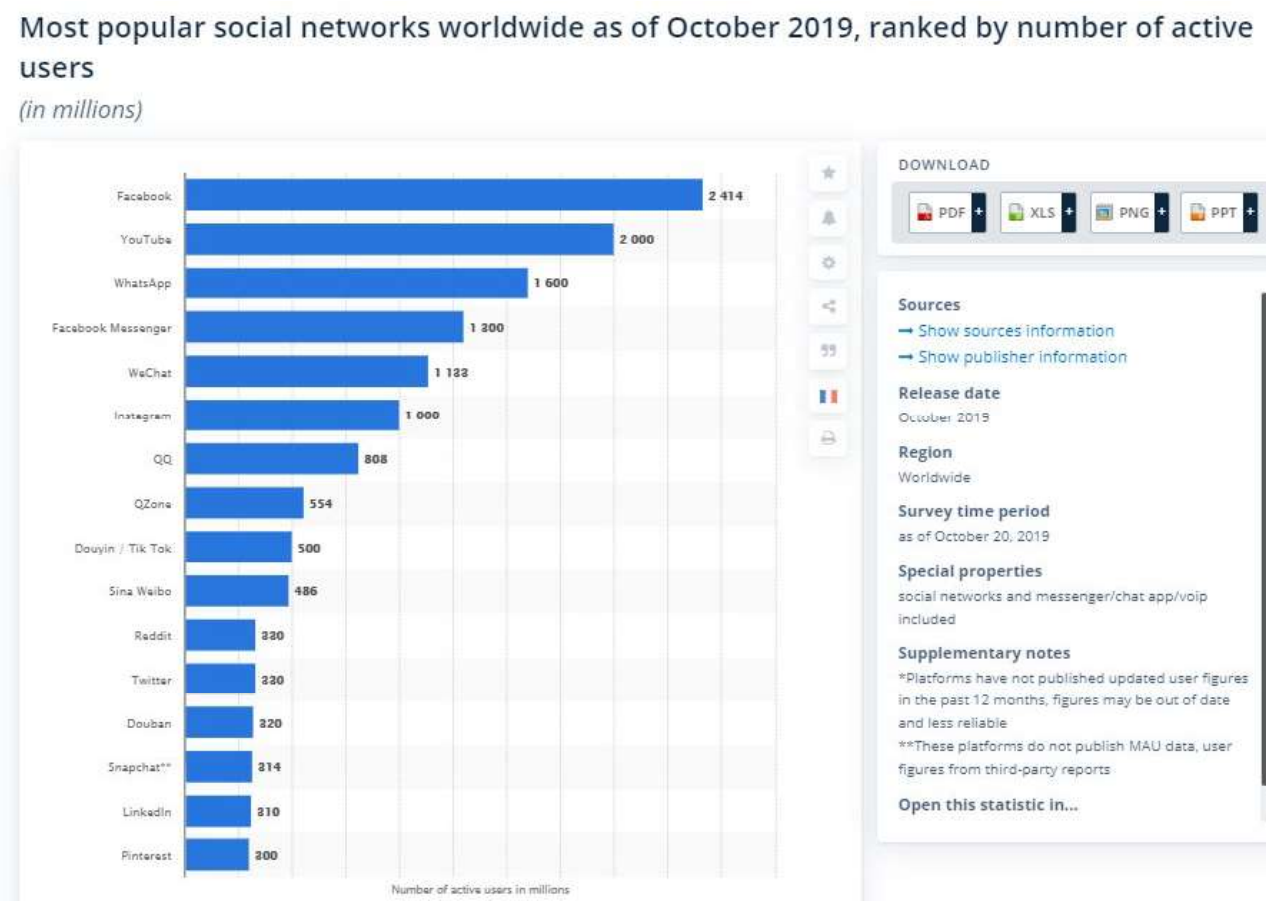

Fonte: https://www.statista.com/statistics/248074/most-popular-us-social-networking-apps-ranked-by-audience/ 
O uso também está afeto a empresas que, em escala crescente, utilizam as redes sociais para interação com os clientes, por meio de inúmeros serviços digitais oferecidos, entre esses, o Serviço de Atendimento ao Consumidor (SAC). O chamado SAC 2.0, serviço de atendimento ao consumidor com suporte em rede social, permite o ajuste de produtos e formas de comunicação, mostrando a tecnologia como protagonista e sendo usada de forma proativa na coleta de informações mercadológicas que podem ser segmentadas por categorias de consumidores predefinidas (LAHOZ, 2016).

\section{A Polícia Federal}

A Polícia Federal brasileira (PF) é subordinada ao Ministério da Justiça e Segurança Pública (MJSP), tendo o legislador constituinte a erigido como órgão permanente, organizado e mantido pela União, e estruturado em carreira, com função de apurar infrações penais contra a ordem política e social ou em detrimento de bens, serviços e interesses da União ou de suas entidades autárquicas e empresas públicas, assim como outras infrações cuja prática tenha repercussão interestadual ou internacional e exija repressão uniforme, segundo se dispuser em lei (artigo 144, \$10 da Constituição Federal de 1988).

A função policial é, por natureza, dirigida ao campo criminal, na investigação de delitos que atentem contra interesses da União, por meio de apurações consubstanciadas em inquérito policial, que identifica autores de crimes, reunindo elementos materiais, de sorte a comprovar a violação ao ordenamento legal.

Além disso, a PF desempenha também atividades administrativas, por excelência, destacando-se o controle migratório no território nacional, de empresas voltadas à segurança privada e transporte de valores, de expedição de documento oficial de viagem (passaporte), de registro e posse de armas de fogo, além do controle e a fiscalização da fabricação e utilização de produtos químicos que possam ser utilizados como insumo na elaboração de drogas ilícitas, entre outras atividades.

Em um breve escorço histórico, a origem da PF remonta ao governo Getúlio Vargas, que, em 1944, criou o Departamento Federal de 
Segurança Pública (DFSP); transferido para a nova capital, Brasília, em 1960. Em 1967, o DFSP recebeu a nomenclatura de Polícia Federal.

A PF exerce funções de natureza policial e administrativa em todo o território nacional, contando, atualmente, com 27 (vinte e sete) Superintendências de Polícia Federal, uma em cada estado e no Distrito Federal, 95 Delegacias de Polícia Federal e 02 Postos Avançados, além de Delegacias de Polícia Marítima - DEPOM espalhadas pelo País.

Da mesma forma, em busca de cooperação com outras polícias do mundo, almejando o fortalecimento de mecanismos de combate aos crimes transnacionais por meio de Acordo sobre Cooperação em operações combinadas de inteligência policial em diversos campos, como por exemplo, terrorismo, tráfico de drogas, tráfico de seres humanos, branqueamento de valores e outros - questões que atualmente se mostram de interesse comum de diversos países -, a PF mantém inúmeras Adidâncias Policiais e Escritórios de Ligação em três continentes (América, Europa e Ásia).

\subsection{Comunicação Social Na PF}

Como soa acontecer nas instituições privadas que possuem setores afetos à comunicação institucional, a PF possui, incrustrada em sua estrutura, a Divisão de Comunicação Social (DCS), subordinada ao Gabinete do Diretor-Geral da Instituição (Portaria n. ${ }^{\circ}$ $1.252 / 2017)$.

Oportuno referir que não há que se confundir - quer nas organizações públicas, quer nas privadas -, a assessoria de imprensa com a comunicação social, pois, enquanto a primeira tem função específica de estabelecer contato com os jornalistas, remetendo informações acerca das atividades de uma organização, bem como mantendo o controle e analisando a informação veiculada na imprensa, a assessoria de comunicação social tem função mais abrangente, tratando do relacionamento, como um todo, de vários atores da opinião pública (DANTAS, 2017). 


\section{Visibilidade MIDiática E REDES SOCIAIS UTILIZADAS PELA POLÍ́CIA FEDERAL}

A visibilidade midiática é fator de grande importância para a PF, cuja marca (valor intrínseco associado à instituição) está intimamente ligada ao combate à corrupção, principalmente os chamados delitos do colarinho branco.

Em que pese o conceito de marca ser associado cotidianamente ao setor privado com o desenvolvimento do conceito de marketing, resta inegável que as instituições públicas também possuem valores vinculados à marca, que lhes atribui características intangíveis, valores, sentimentos, ideias ou afetos, que sobrevalorizam, mesmo em relação à sua prestação funcional (RUÃO, 2003).

O brand equity (valor da marca), de forma incontrastável, também está presente nas instituições públicas que desempenham serviços específicos e originariamente previstos em Lei. O valor marca mostra-se um patrimônio intangível, podendo ser visto sob diversas perspectivas (financeira, econômica e estratégica). Sob o viés estratégico, representa a base de construção do relacionamento com o consumidor, enraizado em seus corações e mentes (SALVADOR, 2015).

E esse valor marca está intimamente ligado à visibilidade midiática pois, diferentemente das empresas onde o cliente possui a percepção direta do produto ou serviço ofertado, a atividade pública, neste caso, da PF, é medida em face de ações de polícia pública investigativa e na prestação de serviços.

É neste campo específico que a visibilidade midiática do Órgão concorre para o valor marca. De acordo com Coelho (2008) a visibilidade midiática contribui para representações associadas à Polícia Federal, eis que são publicizadas marcas de um trabalho específico de combate à criminalidade, com desmonte de esquemas de corrupção, tráfico e fraudes que, muitas vezes, envolvem o próprio poder público (COELHO, 2008).

Resta inconteste que esta visibilidade contribui para a valoração de atributos específicos e imateriais que caracterizam a marca da 
instituição, por meio de uma imagem percebida, pois a sociedade contemporânea é a sociedade das imagens, entendida como uma realidade social permeada pelo predomínio das imagens, onde "estar na imagem é existir para o sujeito atual” (NETO; BACHA; THOMAZ, 2015).

Sob este panorama, as redes sociais, a par das mídias tradicionais que comumente noticiam grandes operações realizadas, inegavelmente contribuem para a valoração do ativo marca. Neste passo, as redes sociais, hodiernamente, tornaram-se ferramentas de utilização obrigatória para a PF, já que a grande característica de partilha simplificada da informação, aproxima a relação com seu público.

Neste campo, a PF faz uso de diversas redes sociais (Facebook, Twitter, YouTube, Instagram, SoundCloud e Flickr), conforme publicado em seu site oficial (http://www.pf.gov.br/), com objetivo de dar a conhecer ao público o trabalho policial realizado, bem como de divulgar notícias de interesse da sociedade em relação a atividades de natureza administrativa.

Portanto, com as redes sociais, esta organização policial almeja alcançar maior proximidade e interatividade com o cidadão e, igualmente, manter o alto grau de confiabilidade perante a opinião pública, buscando um elevado valor marca.

Pesquisa do Instituto Brasileiro de Opinião Pública e Estatística (IBOPE Inteligência), o ICS 2019 (Índice de Confiança Social) apontou a PF como segunda instituição de maior confiança dos brasileiros, com 72 pontos, perdendo apenas para o Corpo de Bombeiros ${ }^{2}$.

No sítio da Polícia Federal na Internet (www.pf.gov.br), no campo "PF nas redes socais", divulga-se o seguinte: o Facebook serve para divulgar o melhor da PF em vídeo, imagem e texto; o Instagram convida o internauta a seguir o perfil e ficar por dentro de tudo o que acontece na instituição; o Twitter convida o internauta a ficar por dentro das principais notícias do órgão; o YouTube serve para divulgar conteúdo de vídeos mais relevantes; o Sound Cloud destina-se a ouvir as coletivas de imprensa e, por último, o Flickr, para baixar as melhores imagens em alta resolução.

2 De acordo com o ranking de acordo com o Índice de Confiança Social (ICS), medido pelo IBOPE Inteligência a, PF ocupou o segundo lugar no índice confiança dos brasileiros. Disponível em: http:// www.aberje.com.br/brasileiro-esta-mais-confiante-nas-instituicoes-diz-ics-do-ibope-inteligencia/ 
Oportuno sublinhar que outros organismos policiais do mundo também utilizam redes sociais para interação com os cidadãos, como exemplo, o FBI (Federal Bureau of Investigation) (https://www. facebook.com/pg/FBI/about/?ref=page_internal), a Polícia Metropolitana de Londres (London's Metropolitan Police Service) (https:// twitter.com/metpoliceuk), a Arma dos Carabinieri (Força de Polícia Italiana) (https://twitter.com/_carabinieri_?lang=es), a Polícia de Investigação do Chile (PDI) (https://www.instagram.com/pdi_chile/?hl=es).

\section{ANÁlise das Redes SOCIAIS EM USO PELA PF E DISCUSSÃO DE RESULTADOS}

Inexiste estudo específico acerca do uso das redes sociais pela PF, havendo somente uma percepção empírica por parte de seu público (interno ou externo), destinatários de tais conteúdos, quanto à sua efetividade e abrangência. Justamente neste aspecto que esta investigação se mostra importante.

Identificadas as redes sociais usadas pela PF, passou-se à análise individualizada de cada uma delas, apontando-se a data de criação, o número de seguidores, o tipo de conteúdo postado (se policial - referente à operação policial ou trabalho investigativo -, data comemorativa ou serviços administrativos desempenhados).

Da mesma forma, analisou-se o número de visualizações, aí incluídas as chamadas curtidas e, ao final, examinou-se as últimas cinco postagens, tendo como marco temporal final da investigação a data de 31 de dezembro de 2019. Verificou-se, contudo, que algumas redes sociais não foram alimentadas ou não sofreram interação há considerável data, conforme será detalhado adiante.

O limite temporal, acima mencionado, justifica-se pelo fato de que, a partir de 2020, o portal institucional da PF migrou para dentro do portal do governo federal (https://www.gov.br/pf/pt-br), tendo ocorrido a descentralização da divulgação de ações, nas redes sociais, por meio das Unidades da PF. 
O gráfico abaixo se mostra relevante neste contexto, no qual é analisado o número de seguidores com base nas informações trazidas pela própria plataforma da rede social examinada.

Gráfico 1. Quantidade de seguidores nas redes sociais da PF

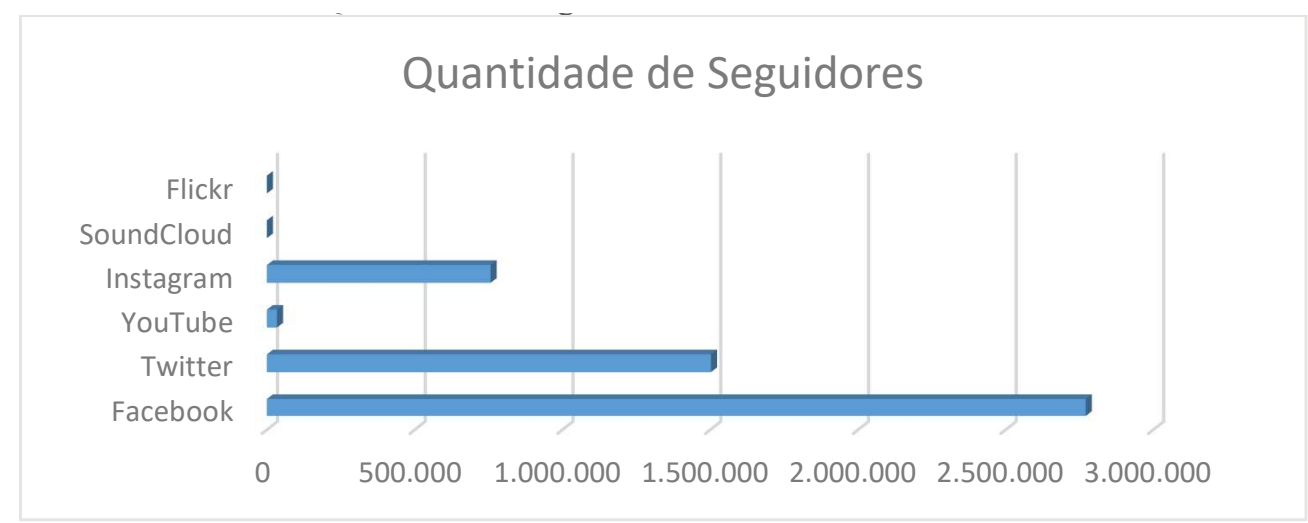

Fonte: elaborado pelo autor

O Facebook, com perfil criado em 2011, é a rede da PF com maior número de seguidores $(2.771 .765 \mathrm{mi})$, destacando-se postagens de natureza policial, com referência a operações e, também, postagens de cunho administrativo (datas comemorativas). O número de visualizações/curtidas é considerável, com grande interação das pessoas inscritas no canal, conforme se pode observar para mensagem de Natal postada no ano em estudo, com 1,2 mil comentários.

Verificou-se que os vídeos postados, referentes a operações policiais noticiadas, trazem o conteúdo (vinheta com duração de 0:09s - PF nas ruas), com um texto na parte abaixo do vídeo, que remete à resenha de imprensa da respectiva operação policial noticiada.

Aqui não se observa a inserção de conteúdo de vídeo relativo à operação policial noticiada, cabendo ao seguidor da rede acessar o respectivo link para alcançar a informação noticiosa escrita.

As publicações são compostas por notícias de operações policiais (em menor escala), datas comemorativas e notícias administrativas (seminários, leilóes e concursos).

No Twitter, com perfil inaugurado em 2010, há cerca de 1,49 mil seguidores, utilizado essencialmente para divulgar operações poli- 
ciais, com notícia que reproduz, em partes sequenciais, após a publicação de post principal, a resenha à imprensa existente no site da instituição (http://www.pf.gov.br/imprensa/noticias).

Isso se torna evidente quando se analisa postagem referente à operação "Pés de Barro" bem como a respectiva notícia divulgada no site oficial do órgão (http://www.pf.gov.br/imprensa/noticias/2019/12/ pf-deflagra-operacao-para-desarticular-esquema-de-superfaturamentos-em-obras-no-sertao-da-paraiba). Aqui igualmente se observa a baixa codificação da mensagem, somente remetendo-se a texto escrito, ausentes imagens, sons ou outros elementos, o que traz baixo fator motivador ao destinatário.

No Twitter, as notícias referentes a operações policiais são publicadas com maior regularidade, enquanto que no Facebook este tipo de publicação é mais esparso.

O YouTube, com perfil criado em 2011 e contando com 34,1 mil seguidores, até 2019 , é utilizado para postagens de natureza administrativa, à exceção do vídeo institucional (Polícia Federal - Institucional/2017), que aparece no topo desta plataforma. Conforme se observa, grande parte das postagens, sobretudo as últimas englobadas pela corporação, são relativas a procedimentos para cadastramento e inserção de documentos no SIPROQUIM (Sistema de Controle e Fiscalização de Produtos Químicos) pelas empresas, usados na forma de tutoriais, ou seja, informações no âmbito da polícia administrativa.

Não se vislumbrou outros conteúdos que poderiam ser disponibilizados nesta plataforma de rede - campanhas educativas de prevenção ao uso de drogas, apreensão de substâncias ilícitas, incineração de entorpecentes, entrevistas de diretores sobre assuntos de interesse público, palestras/aula(s) magna na Academia Nacional de Polícia e outras matérias, igualmente pertinentes para conhecimento do público. Tal fato se mostraria relevante em vista de que o YouTube é um dos maiores sites para carregamento e partilha de vídeos e, também, a segunda maior rede social utilizada, conforme aqui já apontado, o que indica uma subutilização da referida rede social por parte da PF.

O Instagram, com perfil da instituição criado em 2016, conta 
com 753 mil seguidores e, pelo que se verifica, é usado para a postagem de fotos e vídeos, com interação de seguidores através de comentários e curtidas. Entre as postagens analisadas nesta rede social, destacam-se fotos e vídeos inseridos pela Agencia de notícias da PF e por servidores da instituição que referem a atividades de serviço.

Visualizam-se fotos de treinamento policial na Academia Nacional de Polícia, ações de combate ao narcotráfico com uso de cão farejador, fotos de ações policiais em área de selva, ação de combate ilegal ao garimpo clandestino, campanhas educativas (como a alusiva ao dia mundial do enfrentamento ao tráfico de pessoas), bem como seminários e cursos realizados pela instituição (e.g. Seminário com o tema Atividade de Inteligência e o enfrentamento às Organizações criminosas). São postadas mensagens referentes a datas importantes como dia dos pais, dos avós, dia do amigo, Natal e ano-novo.

O número de interações nesta rede, comparado com as outras objetos do estudo, é alto, como, por exemplo, a postagem intitulada "Foto com o cão Golias", da Equipe K9, durante patrulha no rio Paraguai, que teve 7.350 curtidas e 103 comentários.

Os vídeos postados são em menor quantidade, contudo, com considerável acesso, como o vídeo institucional da PF alusivo ao Dia das Crianças, visualizado por 27.777 mil pessoas e o vídeo sobre a Independência do Brasil, com 28,6 mil visualizações e 177 comentários.

Essas situações se adequam ao fato de que uma das características mais marcantes deste aplicativo é seu conteúdo visual, o foco, daí a necessidade de se postarem imagens de alta qualidade e, não, um mero catálogo.

O SoundCloud, ferramenta que permite ao utente compartilhar áudios, bem como tecer comentários acerca de determinado conteúdo postado, não teve sua data de criação visualizada, e conta com 218 seguidores. No caso, é utilizado, conforme mencionado no site oficial, para a postagem de áudio de coletivas de imprensa, quando da deflagração de operações policiais. 
Ao cotejar-se a referida plataforma de rede social, apurou-se que a última postagem de coletiva de imprensa ocorreu em 26/10/2017, época da realização da nominada Operação Lavat, portanto, há mais de dois anos, o que demonstra que tal rede social não é valorada pela instituição, isso é refletido pelo baixo número de seguidores.

Cabe à instituição, neste caso, reavaliar o uso dessa rede social, especialmente a finalidade para a qual foi posta no mercado- disponibilização de conteúdo de áudio (mais específico para criadores de música e áudio e para empresas com campanhas de marketing digital).

Em relação à rede social Flickr, criada em 2016 e, atualmente, com 203 seguidores, também ínfimo número, visualiza-se catálogo de álbuns com 1042 fotos relativas a operações e eventos da PF, separadas em 08 álbuns - fotos históricas, meio ambiente, VANT (Veículo Aéreo não Tripulado), solenidades, Polícia Federal em ação, perícia criminal, COT (Comando de Operações Táticas) e solenidades-; a maior quantidade de fotos consta no álbum Polícia Federal em Ação, com 613 fotos e 1807 visualizações (https://www.flickr.com/photos/policiafederal/albums).

O número de seguidores é extremamente baixo para a instituição PF, notadamente em face de que as imagens de ações e trabalhos do Órgão, que alcança todos os rincões brasileiros, são elementos essenciais para a construção da identidade e da memória da instituição.

Grande parte das imagens são muito antigas, como as do álbum meio ambiente, datadas de mais de uma década (2008 e 2009); do álbum COT (2014); perícia (2012); aeronaves (2009); VANT (2016); Solenidades (2018) e Polícia Federal em Ação (2018).

Observa-se que preciosa ferramenta posta à disposição pela era tecnológica que vivenciamos, e em vista de que, na atualidade, telefones com capacidade de registro fotográfico são de uso comum, poderia trazer imagens surpreendentes, contudo, não é adequadamente utilizada, ausentes postagens de fotografias contemporâneas, fato esse que, indiscutivelmente, acarreta inexpressivo número de seguidores. 
Gráfico 2. Quantidade de visualizações/curtidas

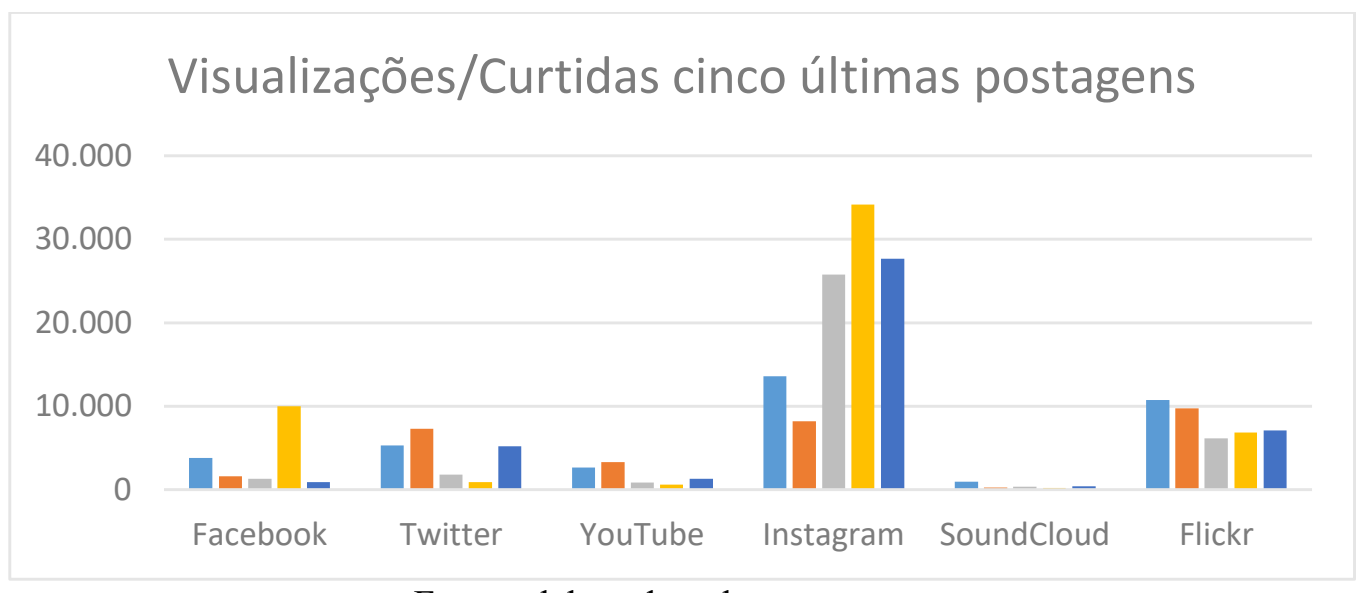

Fonte: elaborado pelo autor

Gráfico 3. Natureza das cinco últimas postagens (postagem referente à atividade policial ou administrativa)

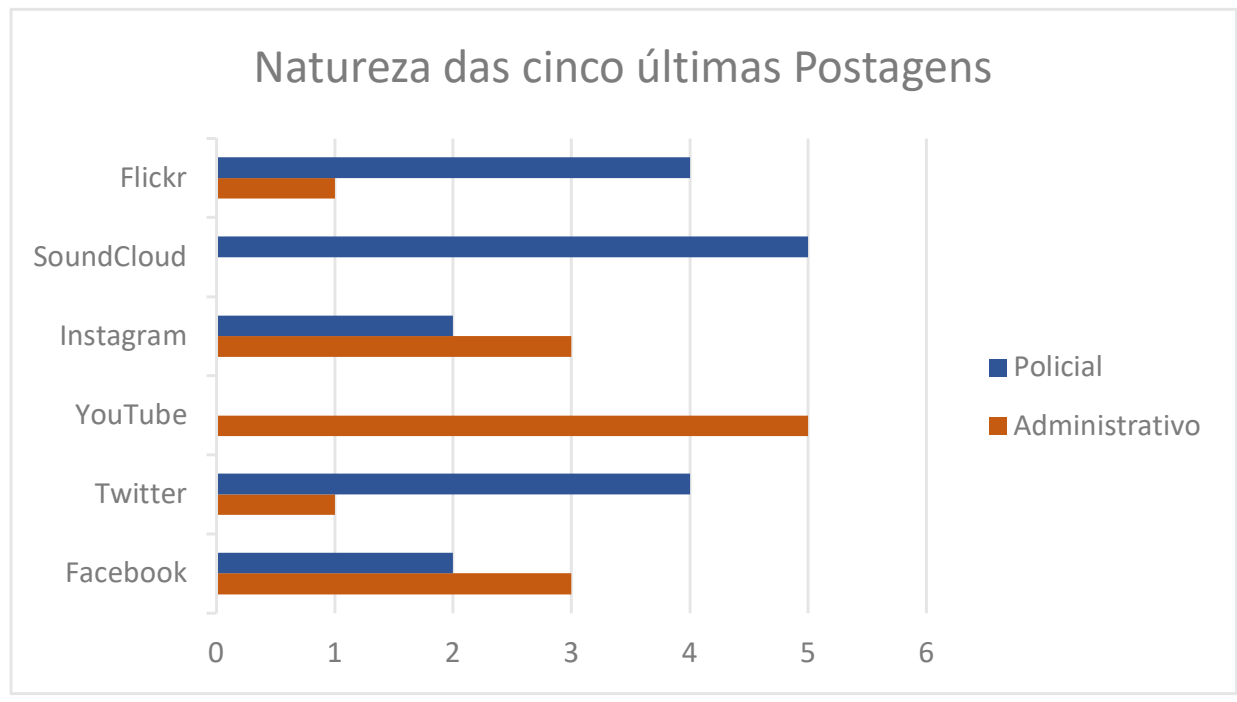

Fonte: elaborado pelo autor 
Gráfico 4. Data da última postagem por aplicativo de rede social da PF, representando a constância de atualizações de cada plataforma

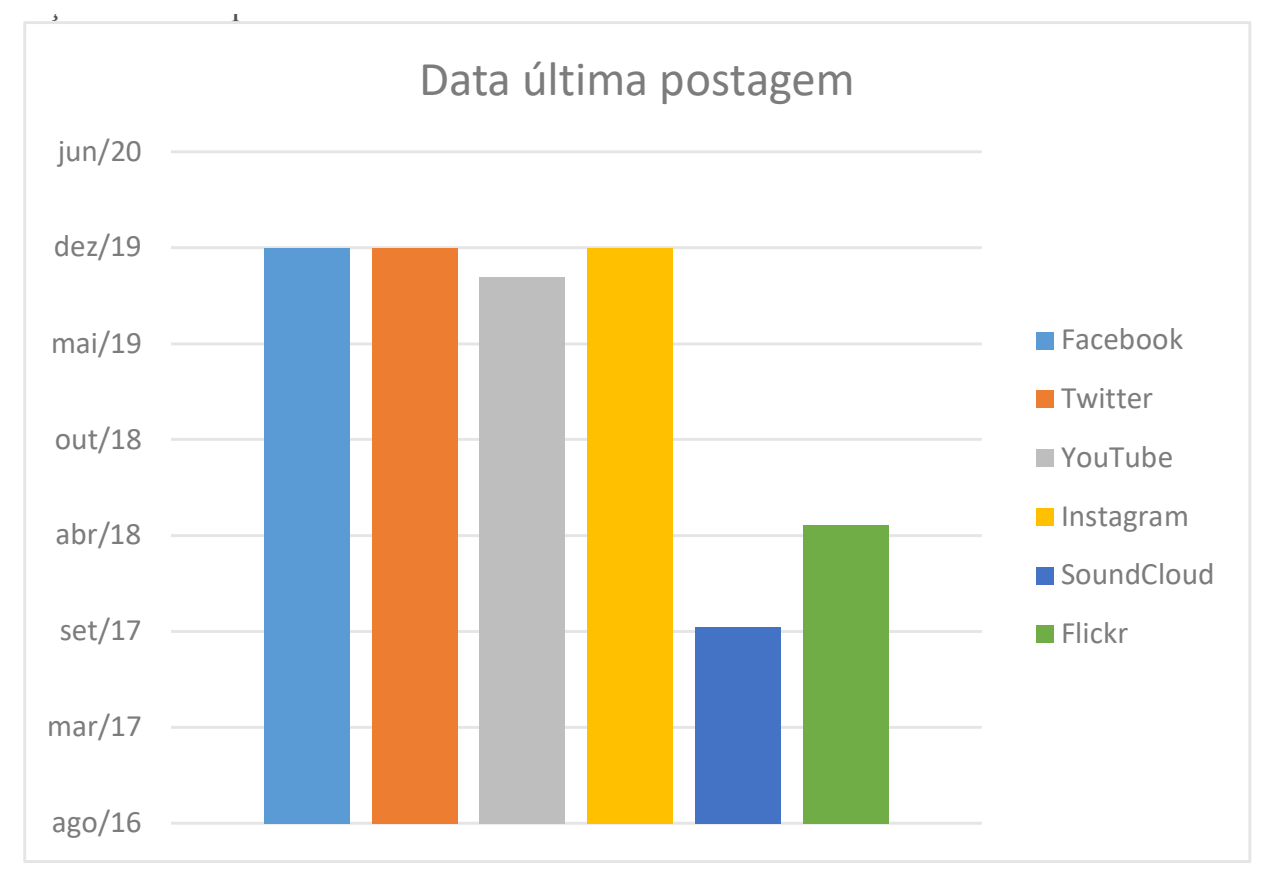

Fonte: elaborado pelo autor

Do contexto trazido, afere-se o uso inadequado de determinadas redes sociais pela PF, bem como a falta de atualização na inserção de informações de caráter noticioso e informativo, seguindo uma tendência atual, contudo, com baixo impacto. Conforme menciona Kunsch (2007), a eficácia e a efetividade no uso das mídias digitais requerem um diagnóstico situacional adequado da realidade da organização, bem como um planejamento bem elaborado, sob pena de o uso representar um simples modismo.

Igualmente, constata-se que não são utilizados elementos de multimídia, tão presentes nas tecnologias atuais postas à disposição, que permitem combinar inúmeros recursos na mesma unidade (textos, fotografias, vídeos, som, gráficos interativos), causando, assim, maior atenção e conectividade do recebedor da mensagem.

O som (a música), também ausente em grande quantidade de postagens, mostra-se de extrema valia para a formulação da estratégia do destinador da mensagem, buscando envolver o receptor na propaganda e remetendo-o a uma experiência emotiva e sensorial com a 
marca (PF), sendo responsável por estabelecer o tom da mensagem, pontuando o desenvolvimento do enredo (CARDOSO; GOMES; FREITAS, 2010) uma poderosa estratégia publicitária em anúncios de televisão, tem recebido pouca atenção por parte dos acadêmicos , quando comparada com outras estratégias.

\section{CONSIDERAÇôES FINAIS}

Percebemos que a nova era tecnológica trouxe inéditos mecanismos para a difusão de informações, como produto da intervenção do homem que redundou em uma materialidade tecnológica e que permitiu flexibilidade e interatividade nas relações, sobressaindo-se, neste contexto, o crescente uso de redes sociais, quer por pessoas, empresas privadas ou organismos públicos.

As instituições públicas igualmente atentaram para a necessidade de ingressar no mundo virtual, como forma de se comunicar com os destinatários de seus serviços, desapegando-se, de certa forma, dos meios comezinhos de transmissão de informação e das mídias tradicionais quando da divulgação de suas ações.

Neste espaço interconectado, a PF, vista como órgão policial de excelência no sistema investigativo penal brasileiro, faz uso de algumas plataformas de redes sociais, como sói acontecer com outros organismos policiais do mundo (FBI, Scotland Yard), como forma de aprimorar o elo com os cidadãos, buscando maior interação com o público e informando de maneira adequada.

A análise das redes sociais utilizadas pela PF mostrou grande receptividade dos seguidores no Facebook, Instagram e Twitter, contudo, chama a atenção o fato de algumas redes, até o período da investigação, não serem adequadamente utilizadas (YouTube, Flickr); e, em outros casos, ausente a atualização de postagens e informações que deveriam ser repassadas aos destinatários conectados.

Ao nosso entendimento, parece que as Unidades policiais localizadas na base da organização não estão devidamente engajadas neste papel tão importante, representado pela difusão de informações 
através de redes sociais, carecendo de alimentar o escalão central, responsável pela comunicação social de material digital pertinente, e isso se deve, em grande parte, à cultura, ainda enraizada nos integrantes da instituição, de que a divulgação do trabalho policial dá-se essencialmente por meio de resenhas dirigidas às mídias tradicionais.

Tal fato chama a atenção, em especial em razão do grande reconhecimento que a PF detém perante a opinião pública, sendo motivo de admiração e por muitos vista, conforme se observa das postagens, como órgão que representa simbolicamente o combate à criminalidade nominada colarinho branco.

Oportuno e relevante destacar que as mudanças ocorridas a partir de 2020, mencionadas no texto, e que estabeleceram o recorte temporal desta pesquisa, poderão ser objeto de novo estudo, de modo a se avaliar o grau de evolução e receptividade por parte dos públicos e quanto a eventuais inovaçôes no uso das redes sociais pela PF.

Não se pode perder de vista que as redes sociais são preciosos instrumentos que devem ser utilizados adequadamente e de forma profissional. O simples uso de determinada rede social, por modismo, pode, muitas vezes, trazer resultado inverso, vindo a comprometer a marca e a imagem da instituição.

Em conclusão, as empresas e os organismos públicos, ao utilizarem poderosas ferramentas postas à disposição pelas plataformas sociais, devem atentar-se ao fato de que estão lidando com instrumentos de transmissão de informação, com um conjunto de atores individuais, grupos, organizações, comunidades que estão em constante interação e troca; o que pode resultar, quando do emprego errôneo ou deficiente de tais meios tecnológicos, em desconexão e desinteresse com o ator principal, responsável pela administração e comunicação de determinada rede social. 
João Carlos Girotto

Delegado de Polícia Federal

Mestrando em Comunicação e Media pelo

Politécnico de leiria (Portugal).

Pós-graduado em Direito Ambiental pela Pontifícia

Universidade Católica (PUC) de Minas Gerais.

Pós-graduado em Gestão de Emergências e Desastres

pela Universidade Gama Filho (UGF).

Pós-Graduado em Altos Estudos de Política e

Estratégia (Escola Superior de Guerra - ESG).

Graduado em Direito pela Universidade de Cruz Alta

(UNICRUZ)

http://lattes.cnpq.br/2655066076397978

\section{EXTERNAL COMMUNICATION IN THE BRAZILIAN FEDERAL POLICE WITH THE USE OF SOCIAL NETWORKS}

\section{ABSTRACT}

With the increasing diffusion of communication and information technologies, the use of social media is present in all classes and layers of society, which use such digital platforms to interact, exchange and share knowledge and information. In this context, private companies and public institutions also started to use this digital space; those seeking to expand their market, increase customer loyalty and sales; these, in turn, fulfilling a normative function of social interest, consisting in bringing information to the citizen, the recipient of their services, as well as improving their image and degree of credibility with the public, through an adequate communication of the activities carried out on a daily basis. In this scenario, the article under review, analyzes the social networks currently used by the Brazilian Federal Police (PF), observing their reach, currentness and receptivity of the public that shares these digital platforms.

KEYWORDS: social medias; Federal Police; network society; digital platforms; internet. 


\title{
LA COMUNICACIÓN EXTERNA EN LA POLICÍA FEDERAL BRASILEÑA CON EL USO DE REDES SOCIALES
}

\begin{abstract}
RESUMEN
Con la creciente difusión de las tecnologías de la información y la comunicación, el uso de las redes sociales está presente en todas las clases y estratos de la sociedad, que utilizan dichas plataformas digitales para interactuar, intercambiar y compartir conocimientos e información. En este contexto, empresas privadas e instituciones públicas también comenzaron a utilizar este espacio digital; aquellos buscando expandir su mercado, lealtad de los clientes y aumentar las ventas; estos, a su vez, cumpliendo una función normativa de interés social consistente en acercar información al ciudadano, destinatario de sus servicios, así como mejorar su imagen y grado de credibilidad ante el público, mediante una adecuada comunicación de las actividades diarias. En este escenario, el artículo en revisión analiza las redes sociales actualmente utilizadas por la Policía Federal Brasileña (PF), observando su alcance, actualidad y la receptividad del público que comparte estas plataformas digitales
\end{abstract}

Palabras-Clave: redes sociales; Policía Federal; sociedad en red; plataformas digitales; internet. 


\section{REFERÊNCIAS}

APÓS 17 anos Bélgica decide encerrar serviços de telegrama. $O$ Globo. 17/12/2017. Economia. Disponível em: https://oglobo. globo.com/economia/apos-171-anos-belgica-decide-encerrarservico-de-telegramas-22205404. Acesso em: 08 jul. 2021.

ASSUNÇÃO, A. B.; JORGE, T. de. M. As mídias sociais como tecnologias de si. Revista Esferas, p. 151-160, 2019. Disponível em: https://portalrevistas.ucb.br/index.php/esf/article/view/5331/3644. Acesso em: 12 ago. 2019.

BENATTI, L. Internet: a grande invenção dos últimos 25 anos. Revista Exame, São Paulo, 9 out 2008. Caderno Tecnologia. Disponível em: https://exame.abril.co.br/tecnologia/internet-agrande-invencao-dos-ultimos-25-anos-m0075764/. Acesso em: 15 dez. 2019.

BRASIL. [Constituição (1988)]. Constituição da República Federativa do Brasil: promulgada em 5 de outubro de 1988: atualizada até a Emenda Constitucional n ${ }^{\circ} 103$, de 12-11-2019.

BRASIL. Portaria $n^{\circ} 1.252$, de 29 de dezembro de 2017. Aprova o Regimento Interno da Polícia Federal. Consultado em 16 dez. 2019. Disponível em: https://www.justica.gov.br/Acesso/ institucional/sumario/regimento/policia-federal/policia-federalportaria-1252-2017.pdf. Acesso em: 20 dez. 2019.

CAMPOS, D. R. et. al. A Mídia e suas Perspectivas no Contexto da Propaganda e da Comunicação Mercadológica. Intercom - Sociedade Brasileira de Estudos Interdisciplinares da Comunicação. In: CONGRESSO BRASILEIRO DE CIÊNCIAS DA COMUNICAÇÃO, 32., 2009, Curitiba, PR - 4 a 7 de setembro de 2009. Disponível em: http://www.intercom.org.br/ sis/2012/resumos/R7-2256-1.pdf. Acesso em: 15 ago. 2019.

CARDOSO, P. R.; GOMES, N.; FREITAS, E. S. L. El papel de la música en los comerciales de televisión : el uso estratégico y el impacto en los consumidores. p. 11-35, [S.d.]. Disponível em: file://C:/Users/joaoj/Downloads/183-185-1-PB.pdf. Acesso em: 15 set. 2019. 
COELHO, M. P. Visibilidade e credibilidade: tensionamento entre mídia e Polícia Federal na operação Satiagraha. ENCONTRO DA COMPOLÍTICA, 3., 2009, São Paulo. Anais. Disponível em: http://www.compolitica.org/home/wp content/ uploads/2011/01/marja_coelho_compolitica_rev1.pdf. Acesso em: 20 ago. 2019.

COMUNICAR. In: WISE, dicionário on line de idiomas. Disponível em: https://www.wordreference.com/enpt/wise. Acesso em: 10 out. 2019 .

DANTAS, J. B. A. Midias sociais e assessoria de imprensa : o Twitter como intarface na comunicação com o público. 2017. Disponível em: http://www.bocc.ubi.pt/pag/dantas-juliana-2017-midias-sociaisassessoria.pdf.

ENNE, A. L. S. Conceito de rede e as sociedades contemporâneas. Revista Comunicação e Informação, v. 7, p. 264-273, 2004.

Disponível em: https://www.revistas.ufg.br/ci/article/ download/24452/15165/. Acesso em: 20 out. 2019.

FIALHO, J.; SARAGOÇA, J.; SILVA, C. Descodificando Interaçöes Sociais. pdf. WHITEBOOKS (Org.). Évora: Comunidades \& Colecções, 2017.p. 33. Disponível em: http://dspace.uevora.pt/ rdpc/handle/10174/22409. Acesso em: 20 out. 2019.

GRASSI, C.; MARQUES, A. D. Análise de conteúdo em redes sociais: metodologia para uma marca de moda. Cimode, p. 240-247, 2018. Disponível em: https://repositorium.sdum.uminho.pt/ handle/1822/55260. Acesso em: 22 out. 2019.

HUGO, V.; PAIVA, V.H. P. Redes e mídias sociais na internet : realidades e perspectivas de um. p. 59-73, 2011. Disponível em: https://repositorio-aberto.up.pt/handle/10216/72485. Acesso em: 10 dez. 2019.

ÍNDIA envia último telegrama. G1.15/06/2013. Tecnologia e Games. Disponível em: http://g1.globo.com/tecnologia/ noticia/2013/06/india-envia-ultimo-telegrama.html. Acesso em: 08 jul. 2021.

KARNAL, L. A revolução do bolso. Jornal Estadão, São Paulo, 29 dez. 2019. Caderno Cultura. Disponível em https://cultura.estadao. 
com.br/noticias/geral,a-revolucao-de-bolso,70003138378. Acesso em: 20 dez. 2019.

KUNSCH, K.; MARGARIDA. M. Comunicación organizacional en la era digital: contexos, recursos y posiblidades. Revista Signo y Pensamiento.v. 26, p. 38-51, 2007.

LAHOZ, D. B. As práticas comunicacionais do pós-venda: o SAC na era das redes sociais on-line. Dissertação (Mestrado em comunicação social). Universidade Metodista de São Paulo (UMESP), 2016. Disponível em: http://tede.metodista.br/jspui/bitstream/ tede/1552/2/Deise\%20Balek\%20Lahoz.pdf. Acesso em: 20 set. 2019.

MARTINS, et. al. Impacto Tecnológico da Informação na Sociedade. Revista Maiêutica, v. 3, n. 47, p. 51-54, 2018. Disponível em: https://publicacao.uniasselvi.com.br/index.ph. Acesso em: 05 jul. 2019.

NETO, C. F.; BACHA, M. de. L.; THOMAZ, J. C. CONGRESSO INTERNACIONAL COMUNICAÇÃO E CONSUMO, 2015, São Paulo. A Trilogia da Marca e a Comunicação do Pão de Açúcar. PPGCOM ESPM.

PEREIRA, D. M.; SILVA, G. S. As Tecnologias de Informação e Comunicação (TICs) como aliadas para o desenvolvimento. Cadernos de ciências sociais aplicadas, v. 10, n. 10, p. 151-174, 2012.

PEREIRA, F.; MATOS, M. Cyberstalking entre adolescentes: uma nova forma de assédio e perseguição?. Psicologia, saúde e doenças, v. 16, n. 1, p. 57-69, 2015. DOI 10.15309/15psd160207. Disponível em: http://dx.doi.org/10.15309/15psd160207. Acesso em: 20 out. 2019.

RUÃO, T. As marcas e o valor da imagem: a dimensão simbólica das actividades económicas. 2003. Disponível em: http://repositorium. sdum.uminho.pt/handle/1822/2726. Acesso em: 20 ago 2019.

SAIOTE, J. Comunicação de Ciência nas Redes Sociais. Porto: [s.n.]. Disponível em: https://repositorio-aberto.up.pt/ handle/10216/72485. Acesso em: 15 ago. 2019.

SALAVERRÍA, R. Aproximación al concepto de multimedia desde los planos comunicativo e instrumental. 
Estudios sobre el Mensaje Periodístico 2001, n. 7: 383-395.

Disponível em: https://dadun.unav.edu/bitstream/10171/5068/1/ esmp_multimedia.pdf. Acesso em: 25 out. 2019.

SALVADOR, A. O uso das informações do big data na gestão de crise de marca. Faculdade de Economia e Administração. 2015. Disponível em: https://teses.usp.br/teses/disponiveis/12/12139/tde-01102015144508/pt-br.php. Acesso em: 20 dez. 2019.

SANTOS, F. R. A Grande árvore genealógica humana. Belo Horizonte. Revista UFMG, v. 21, n. 1 e 2, p. 88-113, jan./dez. 2014.

SUBTIL, F. Tecnologia, economia e política: o telégrafo como antecessor da Internet. Estudos em Comunicação, v., n.15 Esp, p. 25-40, 2014. Disponível em: https://repositorio.ipl.pt/ handle/10400.21/3710. Acesso em: 25 set. 2019. 